\title{
Carnitine Alterations in Spontaneous and Drug- Induced Turkey Congestive Cardiomyopathy
}

\author{
MARY ELLA M. PIERPONT, DIANNE JUDD, BARBARA BORGWARDT, GEORGE R. NOREN, \\ NANCY A. STALEY, AND STANLEY EINZIG
}

\author{
Departments of Pediatrics, Laboratory Medicine and Pathology, University of Minnesota and Veterans \\ Administration Medical Center, Minneapolis, Minnesota 55455
}

\begin{abstract}
Carnitine and acylcarnitines were measured in plasma and tissues of control turkeys, turkeys with an inbred spontaneous cardiomyopathy, and turkeys with furazolidone-induced cardiomyopathy. Heart failure was evident in both types of cardiomyopathy from decreased systemic blood pressure and cardiac dilatation compared to controls. Plasma free carnitine, short-chain acylcarnitine, and long-chain acylcarnitine were significantly elevated by 76 to $614 \%(p<0.01)$ in the two cardiomyopathy models compared to control. The highest carnitine levels were found in the most hypotensive turkeys. Liver free carnitine and short-chain acylcarnitine levels were also elevated by 45 to $537 \%(p<0.05)$ in both types of cardiomyopathy. Free carnitine was elevated by $126 \%$ in left ventricle and by $54 \%$ in skeletal muscle of the furazolidone-treated turkeys $(p<0.05)$. We speculate that hepatic synthesis of carnitine may be increased in response to hypotension and progressive cardiac dysfunction in cardiomyopathic turkeys. Such an increase may be useful to promote $\beta$-oxidation of fatty acids as a cardiac energy source. (Pediatr Res 19: 415-420, 1985)
\end{abstract}

\section{Abbreviations}

SC, spontaneous inbred turkey cardiomyopathy

FC, furazolidone-induced turkey cardiomyopathy

PEP, preejection period

LVET, left ventricular ejection time

CoA, coenzyme A

Carnitine, 3-hydroxy-4-N-trimethylaminobutyric acid, is an essential cofactor for transport of long-chain fatty acids across the inner mitochondrial membrane. Since long-chain fatty acids are a preferred energy substrate of cardiac tissue, $(22,38)$ alterations in carnitine metabolism may contribute to the pathogenesis of cardiac dysfunction in cardiomyopathy. Tissue carnitine deficiency has been documented in humans with endocardial fibroelastosis (36), humans with congestive cardiomyopathy (39), dystrophic cardiomyopathic hamsters (2), and rats with pressureoverload myocardial hypertrophy (28). Plasma (or serum) carnitine has been reported as low $(36,39)$, elevated (37), or normal $(8,28)$ in altered myocardial states. In addition, diabetes $(31)$, fasting $(21)$,and myocardial ischemia $(14,29)$ are associated with alterations in liver and heart carnitine levels.

Received May 29, 1984; accepted December 19, 1984.

Correspondence and reprint address Dr. Mary Ella M. Pierpont, Box 94 Mayo Building University of Minnesota, Minneapolis, MN 55455.

Supported in part by a Basil O'Connor grant from the March of Dimes-Birth Defects Foundation and by grants from the Vikings Children's Fund, the Minnesota Medical Foundation, and the American Heart Association, Minnesota Affiliate.
The present report describes alterations in carnitine and acylcarnitines in plasma and tissues of domestic turkeys with congestive cardiomyopathy. Two distinct types of turkey cardiomyopathy were investigated. The first is a SC preserved in an inbred flock. At 2 months of age, greater than $70 \%$ of the turkeys have marked cardiac dilatation, involving predominantly the left ventricle. Their congestive cardiomyopathy has been previously characterized with respect to histopathology (23), hemodynamics (10), cellular electrophysiological changes (9), regional myocardial blood flow (11), cardiac nucleoproteins $(17,18)$, and altered sarcoplasmic reticulum function (33). Although the etiology of this cardiomyopathy is not precisely known, and may be viral in origin (23), recently demonstrated nucleoprotein phosphorylation changes suggest a genetic etiology $(17,18)$.

The second type is a FC associated with ingestion of furazolidone, a nitrofuran antibiotic used for prophylaxis and treatment of gram-negative bacterial disease of turkeys $(6,7,15,32)$. This cardiomyopathy may result from furazolidone interference with the conversion of pyruvate to acetyl $\operatorname{CoA}(7,13,32)$. To produce this cardiomyopathy, normal turkeys receive furazolidone in their feed continuously from hatching onward. At the age of 2 months, left ventricular dilatation, systemic hypotension, congestive cardiomyopathy, and hepatic dysfunction are present $(6,18$, 32 ).

The present study reveals that turkeys with both types of cardiomyopathy have elevated plasma free carnitine and acylcarnitines as well as increased carnitine levels in some tissues. The most striking alterations in carnitine levels are present in turkeys with the most severe cardiomyopathy and hemodynamic derangements.

\section{MATERIALS AND METHODS}

Broad-breasted white turkeys (Nicholas) for controls were obtained from a commercial hatchery (Barron, WI) as newly hatched poults or as fertile eggs. SC turkeys were obtained from random breeding of an inbred flock maintained at the Minneapolis Medical Research Foundation facility, Cokato, MN. All eggs were incubated in a Petersime incubator at $37.5^{\circ} \mathrm{C}$ until hatching. Control turkeys and SC turkeys were fed the University of Minnesota Veterinary School Turkey Ration no. 1 which provides $546 \mathrm{cal} / \mathrm{kg}$ of feed and contains $28 \%$ protein, $2.3 \%$ fat, $3 \%$ fiber, and supplemental vitamins and minerals.

To produce the group of turkeys with FC cardiomyopathy, normal (Nicholas) turkeys were fed the University of Minnesota Turkey Ration no. 1 with added furazolidone $(0.5 \mathrm{~g} / \mathrm{kg}$ feed $)$ from hatching onward (32). The furazolidone was discontinued $24 \mathrm{~h}$ prior to study. All turkeys were allowed free access to feed and water until immediately before study and sacrifice.

Hemodynamic measurements. Systemic arterial pressure was measured in awake, lightly restrained turkeys at the age of 2 months. A 23-gauge Teflon cannula was inserted into a brachial 
artery using local xylocaine anesthesia. Arterial pressure measurements were made using fluid-filled catheters attached to Statham P23Db strain gauges. A lead II electrocardiogram was simultaneously recorded on an Electronics for Medicine multichannel recorder at a paper speed of $100 \mathrm{~mm} / \mathrm{s}$. The preejection period was measured from the onset of the QRS to the upstroke of the arterial pressure; the left ventricular ejection time was measured from the upstroke of the arterial pressure to the dicrotic notch. The measurements were made (average 5-8 beats) with a Numonics Graphics Analyzer (model 1238). The ratio PEP/ LVET, calculated for some turkeys, is an indication of ventricular contractility (18).

Extraction of free carnitine and acylcarnitine. Before sacrifice, the turkeys were weighed, heparinized $(300 \mathrm{U} / \mathrm{kg})$, and arterial blood was withdrawn and placed at $4^{\circ} \mathrm{C}$. Plasma was then removed by centrifugation at $4^{\circ} \mathrm{C}$. The turkeys were anesthetized with $20 \mathrm{mg} / \mathrm{kg}$ sodium thiopental. The hearts were rapidly removed and weighed after atria were trimmed off. Measurements for a dilation index were taken and the tissue immediately frozen on dry ice for later assay. The dilation index is the ratio of the transverse diameter of the left ventricular cavity to the transverse diameter of the left ventricular chamber (cavity plus lateral wall and interventricular septum) (17). Livers and skeletal muscle (red muscle) were frozen immediately and stored at $-60^{\circ} \mathrm{C}$. After rinsing in cold $0.9 \%$ saline, tissue homogenates were prepared from $50-100 \mathrm{mg}$ of left ventricular apex, liver, and skeletal muscle by finely mincing in ice-cold distilled water and homogenization twice in a Polytron PT-20 at a rheostat setting of 10 for $15 \mathrm{~s}$ with a $30 \mathrm{~s}$ cooling period in between. Aliquots from each tissue homogenate were removed for measurement of noncollagenous protein by the method of Lowry et al. (19) using bovine serum albumin as a standard.

Using modifications $(8,26)$ of the procedure of Pearson et al. (25), carnitine from tissues and plasma was separated into free carnitine, short-chain acylcarnitine, and long-chain acylcarnitine. Long-chain acylcarnitine was precipitated from turkey tissue homogenates with perchloric acid $(0.6 \mathrm{M})$. The centrifuged pellet was washed with perchloric acid and recentrifuged. The pellet was incubated in $1 \mathrm{~N} \mathrm{KOH}$ for $2 \mathrm{~h}$ at $50^{\circ} \mathrm{C}$. Following neutralization with $1 \mathrm{~N} \mathrm{HCl}$, precipitation on ice and centrifugation, the supernatant was assayed for carnitine as described below.

The initial supernatant fractions of the first perchloric acid treatment were neutralized with $4 \mathrm{~N} \mathrm{KOH}$, precipitated on ice, and centrifuged. The resulting supernatant fraction was assayed for free carnitine by the method described below. Short-chain acylcarnitines are also acid soluble, so aliquots of the supernatant fraction were treated with $1 \mathrm{~N} \mathrm{KOH}$, incubated at $50^{\circ} \mathrm{C}$ for $1 \mathrm{~h}$, and neutralized by $1 \mathrm{~N} \mathrm{HCl}$. The resulting solution was assayed for carnitine and is a combined measure of free carnitine and short-chain acylcarnitine.

Carnitine assay. Carnitine was assayed in the prepared tissue and plasma extracts by modifications of the methods of McGarry and Foster (20) and Parvin and Pande (24), using L-carnitine as a standard. Duplicate aliquots of extract were added to a reaction mixture $(0.55 \mathrm{ml})$ containing $50 \mathrm{mM}$ HEPES-KOH buffer $\mathrm{pH}$ 7.6, $0.25 \mathrm{mM}$ N-ethyl-maleimide (NEM), and $0.01 \mu \mathrm{Ci}\left[1-{ }^{14} \mathrm{C}\right]$ acetyl coenzyme A (New England Nuclear, Boston, MA). The reaction was initiated by the addition of $0.5 \mathrm{U}$ carnitine acetyltransferase (Sigma, St. Louis, MO) followed by frequent mixing at $25^{\circ} \mathrm{C}$ for $30 \mathrm{~min}$. The reaction was terminated by the addition of charcoal in acidified alcohol (24), followed by equilibration on ice for $30 \mathrm{~min}$. After centrifugation, an aliquot of the supernatant fraction was placed in scintillation fluid and radioactivity counted. In this assay, standard linear curves for L-carnitine were generated from $20-200 \mathrm{pmol}$ carnitine $/ \mathrm{ml}$ reaction mixture. Recovery of added L-carnitine $(5.25 \mathrm{nmol} / \mathrm{ml})$ to turkey plasma was $97 \%$, while recovery of added L-carnitine to extracted turkey plasma was $99 \%$.

Statistical analysis. Standard statistical methods including two-tailed Student's $t$ test for unpaired samples, Welch-Aspin test (when sample variability dictated its use), and least squares linear regression analysis were used in data analysis. Results are considered significant for $p<0.05$.

\section{RESULTS}

Two-month-old turkeys from the spontaneous cardiomyopathy flock and from the group which received furazolidone all had evidence of cardiomyopathy. They all had decreased mean blood pressures (Fig. 1), decreased systolic and diastolic blood pressures, as well as cardiac dilation compared to control turkeys (Table 1). Control turkeys had a mean dilation index of 0.19 , comparable to others in the literature where values below 0.32 are considered normal $(17,18)$. Mean dilation indexes for study groups SC and FC were 0.53 and 0.67 , respectively. These values are also similar to literature values of 0.47 to 0.69 for cardiomyopathic turkeys $(17,18)$.

Both types of cardiomyopathic turkeys (SC and FC) had a significantly lower body weight, which has previously been observed $(17,18)$ and may be attributable to reduced growth secondary to cardiac dysfunction. The heart weight/body weight ratio of the FC turkeys was increased (Table 1) compared to controls as has been documented previously for this type of turkey (18). Due to marked variation in the degree of cardiac dilatation among SC turkeys, there was no statistically significant difference in heart weight/body weight ratios when compared with controls (18). The PEP/LVET ratio, measured only in SC turkeys, was increased $(0.76 \pm 0.20)$ and is similar to the published mean value of $0.78(18)$. This indicated decreased cardiac contractility of the SC turkeys. Normal turkeys have PEP/LVET values of 0.50 , while FC turkeys have reported values of 0.78 (18).

Measurements of carnitine indicated that the cardiomyopathic turkeys (both SC and FC) had significantly elevated plasma levels of free carnitine, short-chain acylcarnitine, and long-chain acylcarnitine compared to controls (Fig. 2). Furthermore, there was a significant inverse correlation between elevated plasma levels of free carnitine and the degree of cardiac compromise evidenced by hypotension (Fig. 3). The highest plasma free carnitine levels were measured in FC turkeys and these same turkeys had the lowest mean systemic blood pressures (Fig. 3). Turkeys with SC cardiomyopathy had intermediate plasma levels of free carnitine and less reduction in blood pressure. Lastly, the lowest plasma

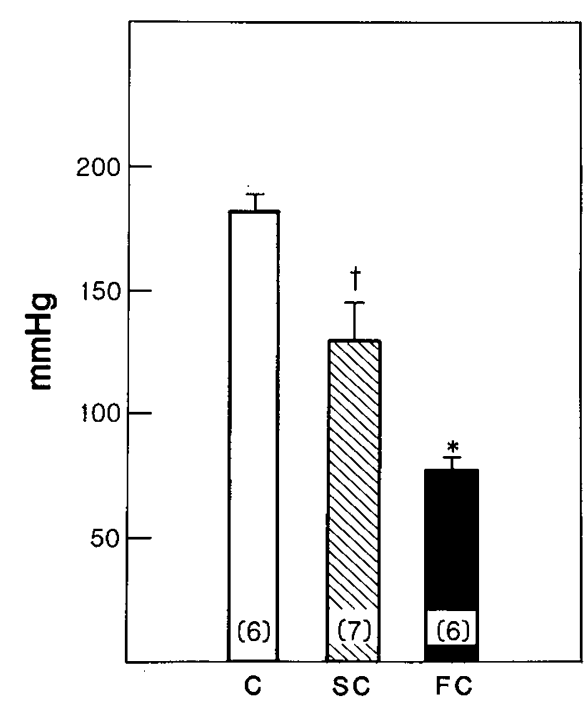

Fig. 1. Mean systemic blood pressure in control and cardiomyopathic turkeys. The height of the bar graphs represents the mean value $\pm \mathrm{SE}$. Numbers in parentheses represent the number of animals. $C$, controls. ${ }^{*} p<0.001 ; \dagger p<0.01$. 
Table 1. Comparison of characteristics of experimental groups (mean $\pm S D$ )

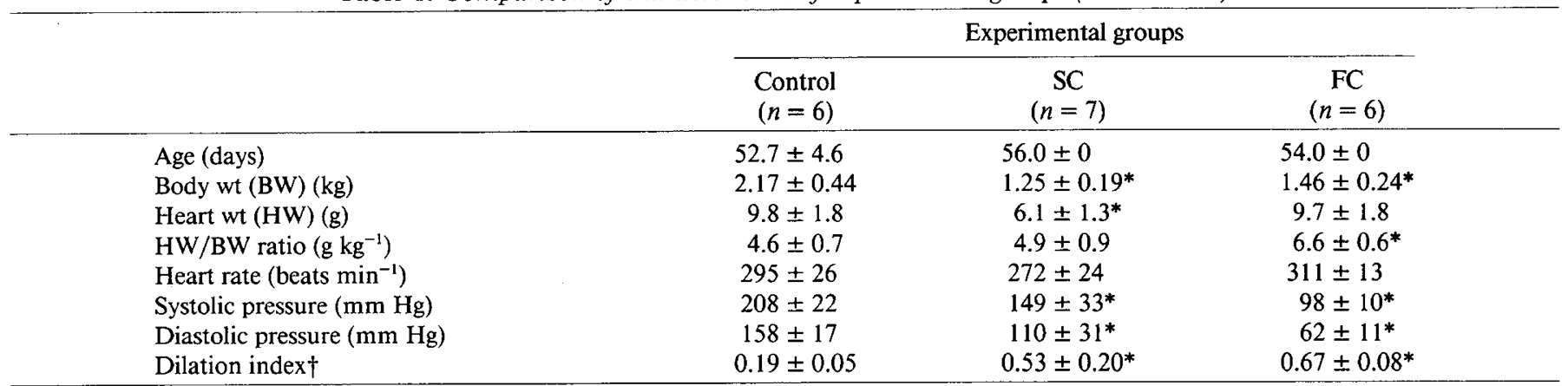

$* p<0.01, \mathrm{SC}$ or FC versus control.

$\dagger$ Dilation index (see text).
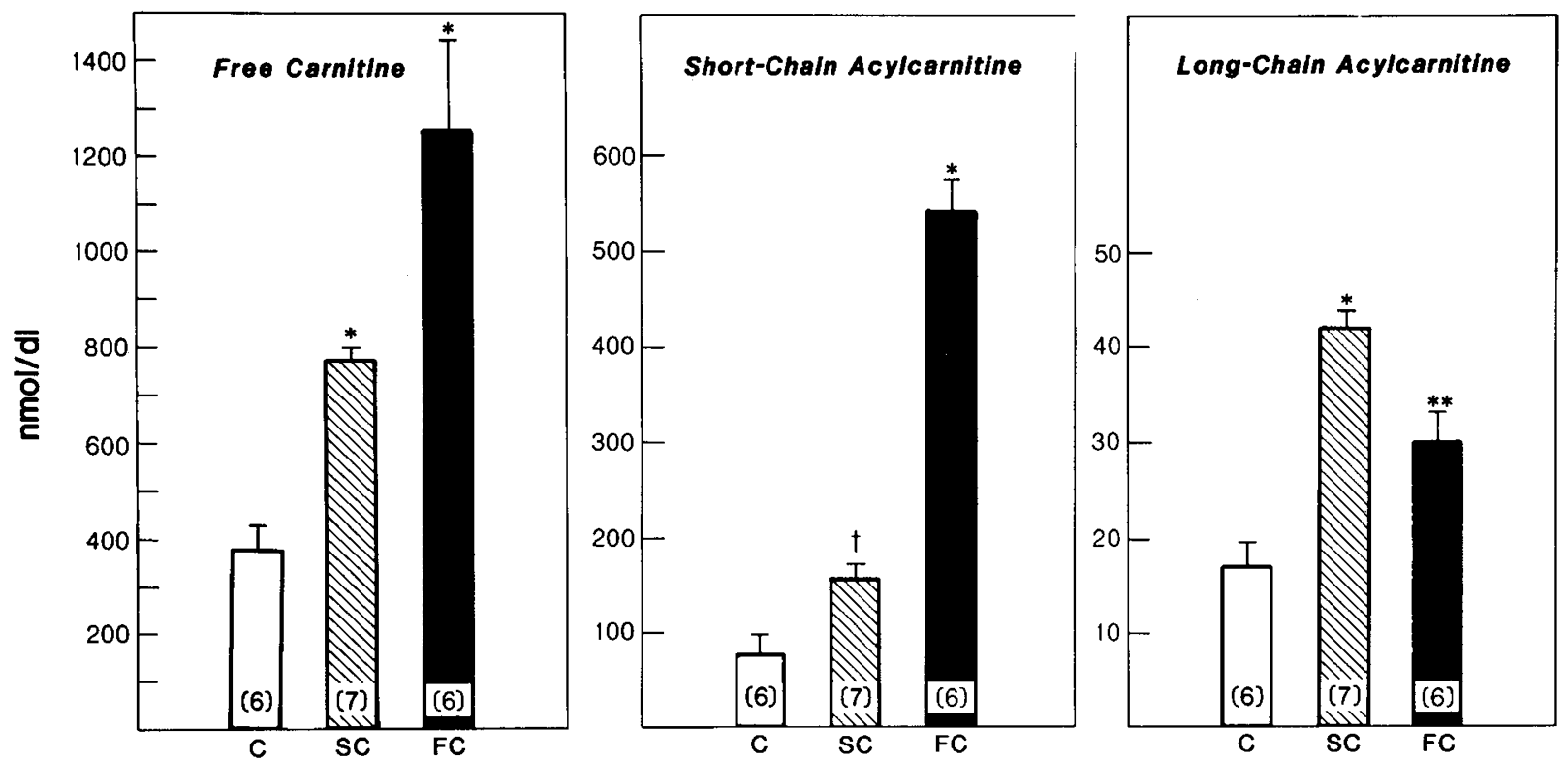

Fig. 2. Plasma free carnitine, short-chain acylcarnitine, and long-chain acylcarnitine (mean $\pm \mathrm{SE}$ ) in control and cardiomyopathic turkeys. ${ }^{*} p<$ $0.001 ;{ }^{* *} p<0.005 ; \dagger p<0.01$.

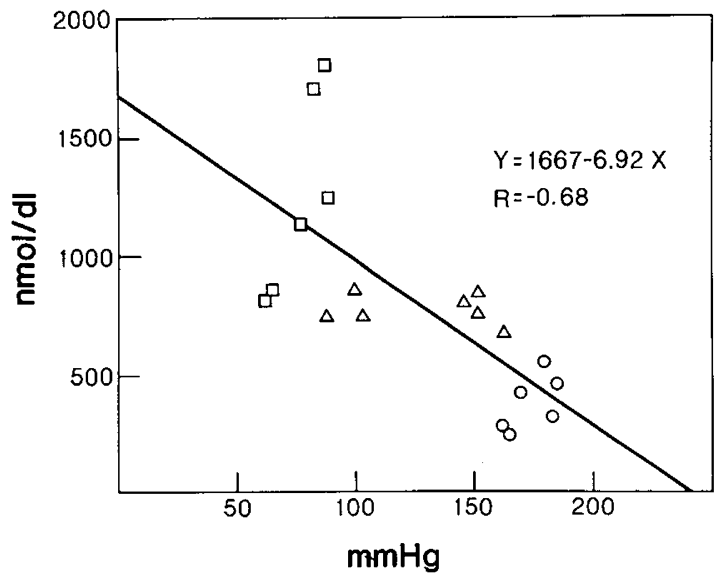

Fig. 3. Least squares linear regression analysis of the relationship between plasma free carnitine and mean blood pressure. $\square$, furazolidoneinduced cardiomyopathy, $n=6 ; \Delta$, spontaneous cardiomyopathy, $n=$ 7 ; o, control, $n=6$.

free carnitine was found in the control turkeys who have the highest (normal) mean blood pressures. Similar inverse relationships exist for mean blood pressure and either plasma shortchain acylcarnitine or plasma long-chain acylcarnitine (not depicted).
Cardiomyopathic turkeys did not have tissue free carnitine or acylcarnitine deficiency. On the contrary, FC turkeys had significantly elevated left ventricular myocardial levels of free carnitine and short-chain acylcarnitine (Fig. 4). Skeletal muscle free carnitine was elevated $(p<0.05)$ in FC turkeys $(441 \pm 42 \mathrm{nmol} /$ $100 \mathrm{mg}$ noncollagenous protein versus $286 \pm 23$ for control and $323 \pm 56$ for SC turkeys). Skeletal muscle short- and long-chain acylcarnitines in the SC and FC turkeys were similar to control values of $98 \pm 7$ and $7.4 \pm 3 \mathrm{nmol} / 100 \mathrm{mg}$ noncollagenous protein, respectively. Finally, liver free carnitine and short-chain acylcarnitine were significantly elevated in both SC and FC turkeys (Fig. 5). Liver long-chain acylcarnitine was elevated in $\mathrm{SC}$ turkeys but not FC turkeys (Fig. 5).

\section{DISCUSSION}

This study was performed to investigate whether any alteration in carnitine metabolism is present in two turkey models of congestive cardiomyopathy. Since congestive cardiomyopathy and myocardial dysfunction have previously been associated with carnitine deficiency $(2,28,36,39)$, the hypothesis tested by our study was that turkeys with spontaneous cardiomyopathy had carnitine deficiency and that this might be different from turkeys with furazolidone cardiomyopathy.

The major findings of this study are that plasma levels of free carnitine as well as short-chain acylcarnitine and long-chain 

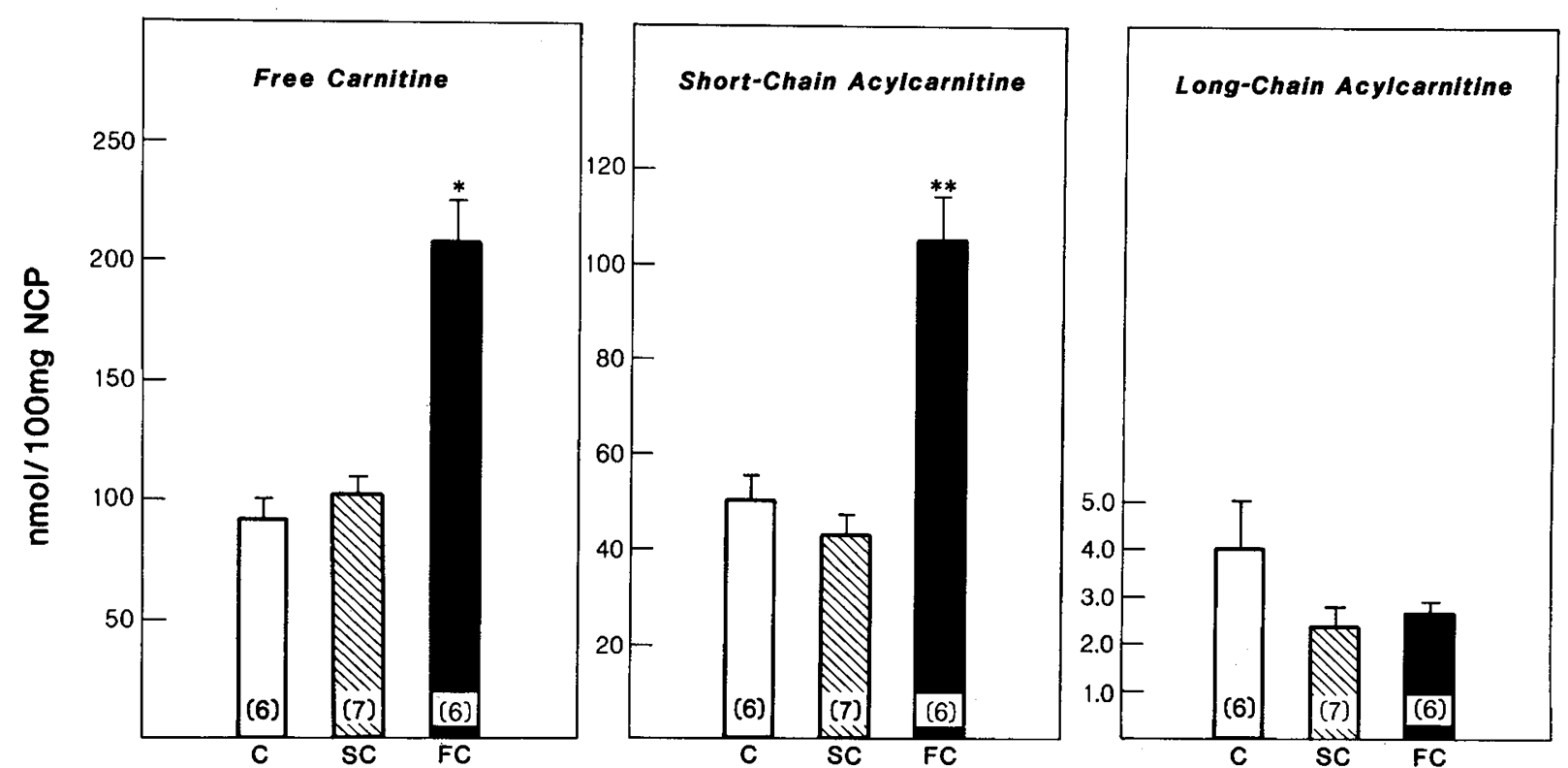

Fig. 4. Left ventricle free carnitine, short-chain acylcarnitine, and long-chain acylcarnitine (mean $\pm \mathrm{SE}$ ) in control and cardiomyopathic turkeys. ${ }^{*} p<0.001 ;{ }^{* *} p<0.005, N C P$, noncollagenous protein.
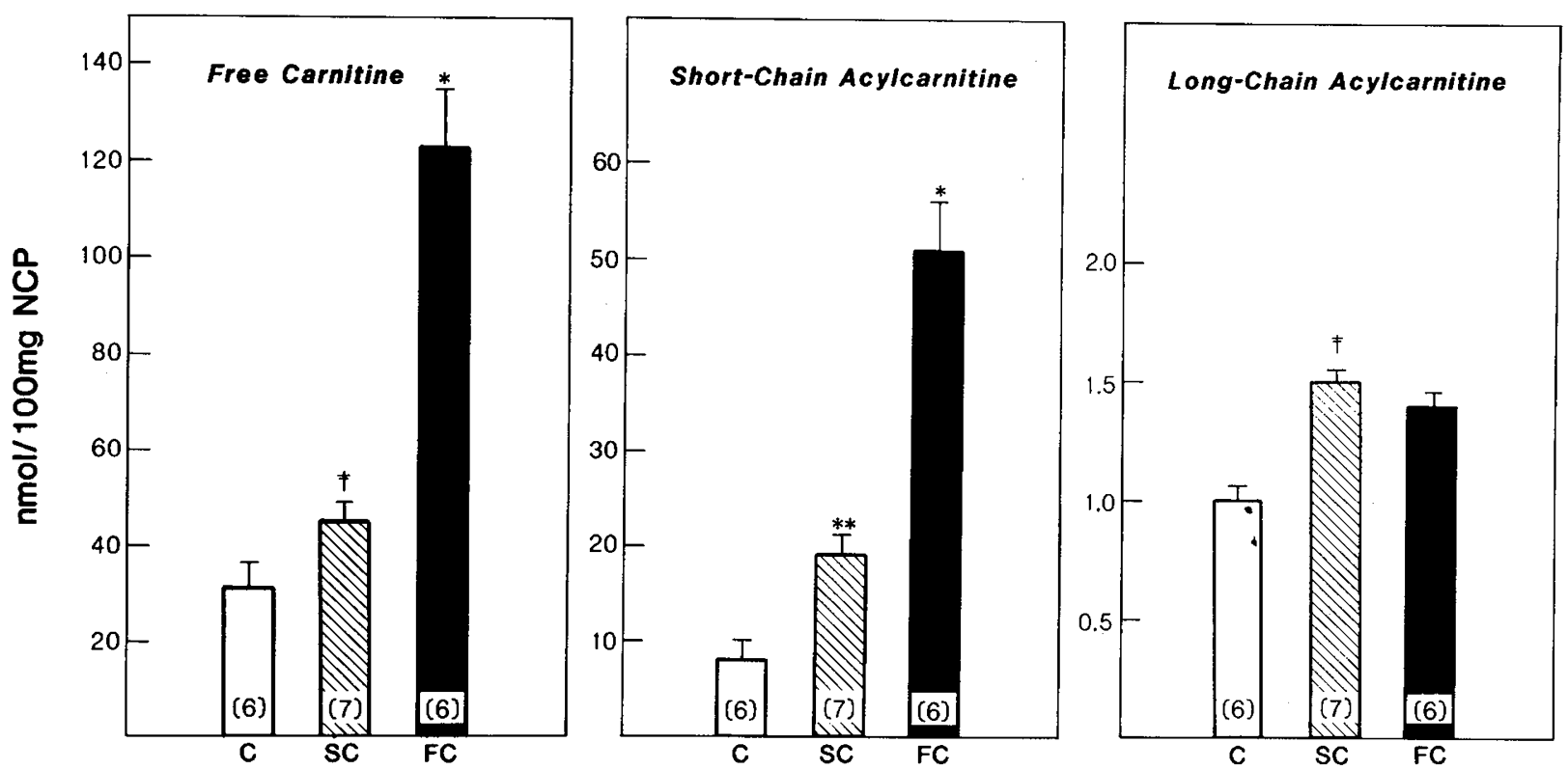

Fig. 5. Liver free carnitine, short-chain acylcarnitine, long-chain acylcarnitine (mean \pm SE) in control and cardiomyopathic turkeys. ${ }^{*} p<0.001$; ** $p<0.005 ; \ddagger p<0.05, N C P$, noncollagenous protein.

acylcarnitine are markedly elevated in both types of turkey cardiomyopathy and, furthermore, the highest plasma carnitine levels are present in the most hypotensive turkeys (FC). In addition, liver free carnitine and short-chain acylcarnitine are elevated in both types of turkey cardiomyopathy. The most hypotensive turkeys (FC) also had the highest liver free carnitine and acylcarnitine, while the elevated liver carnitine levels were not as high in the less hypotensive SC turkeys. Since the liver is a site of carnitine biosynthesis, the plasma and liver carnitine elevations suggest the possibility of increased liver carnitine biosynthesis, perhaps as a response to progressive cardiac failure. Diabetes and fasting (21) are two factors which can elevate liver free and total carnitine levels (presumably by biosynthesis). These conditions were not present in the turkeys utilized in these experiments, since no turkey was deprived of water or feed. We cannot completely exclude a discrepancy in oral intake over the 2 months of study between cardiomyopathic and normal turkeys since we did not measure total feed intake. However, our close monitoring of these turkeys during the study period indicated to us that all turkeys had equal access to water and feed. The body weights of both types of cardiomyopathic turkeys were very similar, yet the liver free carnitine of the FC turkeys was approximately three times higher than SC turkeys (Fig. 5), suggesting that poor oral intake alone cannot account for this difference.

Free carnitine and short-chain acylcarnitine are significantly higher in left ventricular tissue of FC turkeys than in control or SC turkeys. Since it is generally accepted that cardiac tissue cannot synthesize carnitine, this may reflect increased or stimulated transport of free carnitine into myocardial cells because of increased availability of carnitine in plasma. The differences in plasma and tissue levels of carnitine between the two types of turkey cardiomyopathy may suggest different etiologies for each type or, more likely, it may reflect the fact that the FC turkeys of our study were in a more advanced state of myocardial 
decompensation compared to the SC turkeys.

Other conditions causing myocardial dysfunction are known to be associated with marked alterations in carnitine and long chain fatty acid metabolism. Myocardial ischemia with reduced cardiac function is associated with increased myocardial longchain acyl CoA, increased long-chain acylcarnitines, as well as decreased acetyl CoA, short-chain acylcarnitine, free coenzyme $\mathrm{A}$, and free carnitine $(14,35,40)$. Increased long-chain acyl $\mathrm{CoA}$ may inhibit important membrane systems such as adenine nucleotide translocase (29), carnitine palmityl CoA transferase (3), and $\mathrm{Na}^{+}, \mathrm{K}^{+}$ATPase of sarcolemma (41). Similarly long-chain acylcarnitine can interfere with $\mathrm{Na}^{+}, \mathrm{K}^{+}$ATPase, $\mathrm{K}^{+}$phosphatase (41), and calcium binding in the sarcoplasmic reticulum (1). Replacement of carnitine may be of benefit in ischemic hearts $(12,16)$, since it has been demonstrated that such supplementation resulted in more stable cardiac electrical activity, increased tissue high energy phosphates, and restored adenine nucleotide translocase activity (12). Furthermore, carnitine supplementation has been associated with decreased incidence of heart failure in humans with diphtheria (27), improved survival of diphtheric guinea pigs (5), and improved survival of mice treated with doxorubicin (34). Myocardial carnitine levels have been reported as reduced in diphtheric guinea pigs (4), and reduced, but not significantly, in doxorubicin-treated mice (34). It is unclear whether the improved survival in either species is related to normalization of myocardial carnitine.

The effect of carnitine supplementation on mortality and development of cardiac dilation has yet to be determined in these two types of cardiomyopathic turkeys. However, propranolol therapy has been associated with reduced cardiac dilation in furazolidone-supplemented turkeys (13), suggesting that it is valuable to decrease $\beta$-adrenergic drive in these turkeys. Whether the administration of propranolol could also prevent the increase in plasma and tissue carnitines in FC cardiomyopathy is not yet known.

It is interesting to compare the elevated carnitines of these two turkey cardiomyopathies with the fact that some humans with severe congestive cardiomyopathy have elevated plasma carnitine levels (37). It is possible that carnitine metabolism is altered in humans in a manner analogous to our turkeys. Furthermore, this study suggests that myocardial failure influences the regulation of plasma levels of free carnitine and acylcarnitine. In response to hypotension and decreased cardiac output, hepatic biosynthesis of carnitine may be stimulated. This potentially useful increased availability of carnitine to combine with longchain fatty acids may shift the balance toward more $\beta$-oxidation of fatty acids and thus provide the heart and tissues with greater energy supply.

Alternatively, since carnitine is removed from plasma by renal excretion, the data presented here are also consistent with the hypothesis that the increased plasma and tissue carnitine levels are due to decreased renal excretion. Cardiac failure may impair renal function by reducing renal blood flow and thus reducing carnitine excretion. However, previous measurements of renal arterial blood flow in turkeys with SC cardiomyopathy have revealed no significant differences compared to control turkeys (11). Renal blood flow measurements have not yet been made in FC turkeys. Urinary carnitine excretion measurements as well as studies of fatty acid oxidation rates will be informative to define more clearly the mechanisms responsible for the carnitine alterations reported herein.

\section{REFERENCES}

1. Adams RJ, Cohen DW, Gupta S, Johnson JD, Wallick ET, Wang T, Schwartz A 1979 In vitro effects of palmitylcarnitine on cardiac plasma membrane $\mathrm{Na}, \mathrm{K}-\mathrm{ATPase}$, and sarcoplasmic reticulum $\mathrm{Ca}^{2+}-\mathrm{ATPase}$ and $\mathrm{Ca}^{2+}$ transport. J Biol Chem 254:12404

2. Borum PR, Park JH, Law PK, Roelofs RL 1978 Altered tissue carnitine levels in animals with hereditary muscle dystrophy. J Neurol Sci 38:113

3. Bremer J, Norum KR 1967 The mechanism of substrate inhibition of palmity coenzyme A: carnitine palmityltransferase by palmityl coenzyme A. J Biol
Chem 242:1744

4. Bressler R, Wittels B 1965 The effect of diphtheria toxin on carnitine metabolism in the heart. Biochim Biophys Acta 104:39

5. Challoner DR, Mandelbaum I, Elliot W 1971 Protective effect of L-carnitine in experimental intoxication with diphtheria toxin. J Lab Clin Med 77:616

6. Czarnecki CM 1980 Furazolidone-induced cardiomyopathy-biomedical model for the study of cardiac hypertrophy and congestive heart failure. Avian Dis 24:120

7. Czarnecki CM, Reneau JK, Jankus EF 1975 Blood glucose and tissue glycogen levels in turkey poults with spontaneous round heart disease and furazolidone-induced cardiomyopathy. Avian Dis 19:773

8. Dunnigan A, Pierpont ME, Smith SA, Breningstall G, Benditt DG, Benson DW 1984 Cardiac and skeletal myopathy associated with cardiac dysrhythmias. Am J Cardiol 53:731

9. Einzig S, Detloff BLS, Borgwardt BK, Staley NA, Noren GR, Benditt DG 1981 Cellular electrophysiological changes in "round heart disease" of turkeys. A potential basis for dysrhythmias in myopathic ventricles. Cardiovasc Res 15:643

10. Einzig S, Jankus EF, Moller JH 1972 Round heart disease in turkeys: A hemodynamic study. Am J Vet Res 30:557

11. Einzig S, Staley NA, Mettler E, Nicoloff DM, Noren GR 1980 Regional myocardial blood flow and cardiac function in a naturally occurring congestive cardiomyopathy of turkeys. Cardiovasc Res 14:396

12. Folts JD, Shug AL, Koke JR, Bittar N 1978 Protection of the ischemic dog myocardium with carnitine. Am J Cardiol 41:1209

13. Gwathmey JK, Hamlin RL 1983 Protection of turkeys against furazolidoneinduced cardiomyopathy. Am J Cardiol 52:626

14. Idell-Wenger JA, Grotyohann LW, Neely JR 1978 Coenzyme A and carnitine distribution in normal and ischemic hearts. J Biol Chem 253:4310

15. Jankus EF, Noren GR, Staley NA 1972 Furazolidone-induced cardiac dilatation in turkeys. Avian Dis 16:958

16. Liedtke AJ, Nellis SH, Whitesell LF 1978 Effects of carnitine isomers on fatty acid metabolism in ischemic swine hearts. Circ Res 48:1209

17. Limas CJ, Einzig S, Noren GR 1982 Nucleoprotein changes in the hearts of cardiomyopathic turkeys. Cardiovasc Res 16:225

18. Limas CJ, Einzig S, Noren GR 1982 Contrasting effects of spontaneous and induced cardiomyopathy on the nucleoproteins of turkey hearts. Cardiovasc Res 16:263

19. Lowry OH, Rosebrough NJ, Farr AL, Randall RJ 1951 Protein measurement with Folin phenol reagent. J Biol Chem 192:265

20. McGarry JD, Foster DW 1976 An improved and simplified radioisotopic assay for the determination of free and esterified carnitine. J Lipid Res 17:277

21. McGarry JD, Robles-Valdes C, Foster DW 1975 Role of carnitine in hepatic ketogenesis. Proc Natl Acad Sci USA 72:4385

22. Neely JR, Morgan HE 1974 Relationship between carbohydrate and lipid metabolism and the energy balance of heart muscle. Ann Rev Physiol 36:413

23. Noren GR, Staley NA, Jankus EF, Stevenson JE 1971 Myocarditis in round heart diseases in turkeys. Virchows Arch [A] 352:285

24. Parvin R, Pande SV 1977 Microdtermination of (-) carnitine and carnitine acetyltransferase activity. Anal Biochem 79:190

25. Pearson DJ, Chase FJA, Tubbs DK 1969 The assay of (-)-carnitine and its oacyl derivatives. Methods Enzymol XIV:612

26. Pierpont ME, Judd D, Borgwardt B, Noren GR, Staley NA, Einzig S 1982 Carnitine and acylcarnitines in spontaneous turkey cardiomyopathy. Circulation 66 :II-110

27. Ramos AC, Elias PR, Barrucand L, DaSilva JA 1984 The protective effect of carnitine in human diphtheric myocarditis. Pediatr Res 18:815

28. Reibel DK, Uboh CE, Kent RL 1983 Altered coenzyme A and carnitine metabolism in pressure-overload hypertrophied hearts. Am J Physiol 244:H839

29. Shug AL, Thomsen JH, Folts JD, Bittar N, Klein ML, Koke JR, Huth PJ 1978 Changes in tissue levels of carnitine and other metabolites during myocardial ischemia and anoxia. Arch Biochem Biophys 187:24

30. Simpson CF, Rollinghoff W, Preisig R, Fisher MJ 1979 Hepatitis, cardiomyopathy and hemodynamics in furazolidone-induced round heart disease of turkeys. Can J Comp Med 43:345

31. Sinclair-Smith BC 1979 The heart in diabetes mellitus. Tex Rep Biol Med 39:429

32. Staley NA, Noren GR, Bandt CM, Sharp HL 1978 Furazolidone-induced cardiomyopathy in turkeys. Am J Pathol 91:531

33. Staley NA, Noren GR, Einzig S 1981 Early alterations in the function of sarcoplasmic reticulum in a naturally occurring model of congestive cardiomyopathy. Cardiovasc Res 15:276

34. Strohm GH, Payne CM, Alberts DS, Peng YM, Moon TE, Bahl JJ, Bressler R 1982 Cardiotoxic effects of doxorubicin with and without carnitine. Arch Pathol Lab Med 106:18

35. Suzuki T, Kamikawa T, Yamazaki N 1981 Carnitine distribution in subepicardial and subendocardial regions in normal and ischemic dog hearts. Jpn Heart J 22:377

36. Tripp ME, Katcher ML, Peters HA, Gilbert EF, Arya S, Hodach RJ, Shug AL 1981 Systemic carnitine deficiency presenting as familial endocardial fibroelastosis. A treatable cardiomyopathy. N Engl J Med 305:385

37. Tripp ME, Shug AL 1984 Plasma carnitine concentrations in cardiomyopathy patients. Biochem Med 32:199

38. Vary TC, Reibel DK, Neely JR 1981 Control of energy metabolism of heart muscle. Ann Rev Physiol 43:419

39. Waber LJ, Valle D, Neill C, DiMauro S, Shug A 1982 Carnitine deficiency presenting as familial cardiomyopathy: A treatable defect in carnitine trans- 
port. J Pediatr 101:700

40. Whitmer JT, Idell-Wenger JA, Rovetto MJ, Neely JR 1978 Control of fatty acid metabolism in ischemic and hypoxic hearts. J Biol Chem 253:4305
41. Wood JM, Bush B, Pitts BJR, Schwartz A 1977 Inhibition of bovine heart $\mathrm{Na}^{+}$ $\mathrm{K}^{+} \mathrm{ATPase}$ by palmityl carnitine and palmityl CoA. Biochem Biophys Res Commun 74:677

\title{
Respiratory Syncytial Virus-Specific IgE Responses following Infection: Evidence for a Predominantly Mucosal Response
}

\author{
ROBERT C. WELLIVER, MARTHA SUN, DEBORAH RINALDO, AND PEARAY L. OGRA \\ Department of Pediatrics and Microbiology, State University of New York at Buffalo, and Division of Infectious \\ Diseases, Children's Hospital, Buffalo, New York 14222
}

\begin{abstract}
In order to determine whether IgE production occurs predominantly at mucosal or systemic sites, we studied the production of respiratory syncytial virus (RSV)specific antibody in serum and nasopharyngeal secretions (NPS) from 41 patients with RSV infection using an enzyme-linked immunosorbent assay. RSV-IgE was found in higher titer in samples of NPS than in simultaneously obtained serum specimens at all phases of illness. Despite the excess dilution incurred in the collection process, RSVIgE was frequently detected in NPS specimens while it was undetectable in serum. In 20 selected subjects, ratios of RSV antibody in NPS:serum were 2.00 for RSV-IgE, 2.42 for RSV-IgA, and 0.01 for RSV-IgG. Also the geometric mean value of ratios of RSV-IgE:RSV-IgG was 1.74 in NPS and 0.05 in serum, while the geometric mean value of ratios of RSV-IgA:RSV-IgG were 1.85 in NPS and 0.09 in serum. These data suggest that IgE production occurs predominantly at mucosal surfaces. (Pediatr Res 19: 420424, 1985)
\end{abstract}

\section{Abbreviations}

RSV, respiratory syncytial virus

NPS, nasopharyngeal secretions

ELISA, enzyme-linked immunosorbent assay

URI, upper respiratory tract infection

GMT, geometric mean titer

Although the importance of $\operatorname{IgE}$ as a mediator of hypersensitivity diseases has been well established, the site of production of this immunoglobulin isotype remains controversial. Investigations of IgE production in the respiratory tract have demonstrated increased ratios of total IgE to albumin in respiratory secre-

Received September 10, 1984; accepted December 21, 1984

Reprint address Dr. Robert C. Welliver, Division of Infectious Diseases, Children's Hospital, 219 Bryant Street, Buffalo, NY 14222.

Supported by grants from the National Heart, Lung and Blood Institute (HL21829-05), the National Institute of Allergy and Infectious Diseases (AI-15939-01), and the National Institute of Child Health and Human Development (HD-1594302). tions in comparison to serum (1) as well as indirect evidence that grass pollen-specific IgE antibody in nasal secretions is produced locally (2). The study of IgE responses to an infectious agent would allow for an evaluation of the kinetics of IgE production at both systemic and mucosal sites following a single exposure to the antigen. Any potential modulating effects on antibody responses from repeated exposure to an antigen such as grass pollen would therefore be avoided.

$\mathrm{RSV}$ is a common cause of respiratory illness in young infants, and severe forms of illness appear to be mediated, at least in part, by the production of RSV-specific IgE antibody. We undertook the current study of the antibody response in serum and NPS to RSV infection in order to determine whether IgE antibody responses to an infectious agent occur primarily at mucosal or systemic immunocompetent tissue sites. The data suggest that, while RSV infection stimulates a strong antibody response at both sites, IgE antibody to the virus is formed in much greater quantities in the respiratory tract.

\section{MATERIALS AND METHODS}

Patient population and sample collection. The study population consisted of 41 infants less than 1 yr of age either hospitalized due to RSV infection or followed as part of an ongoing study of respiratory illnesses in childhood. At the time of recruitment into the study, the objectives and risks of the study were explained and a signed statement of informed consent was obtained. Patients were classified as having either URI alone, pneumonia, or bronchiolitis on the basis of clinical and radiographic criteria described in previous publications from this laboratory (3). According to these criteria, nine patients had URI alone, five had pneumonia without wheezing, and 27 had bronchiolitis. All patients had been in good health until the time of RSV infection.

Samples of NPS were obtained at the time of recruitment by passing an 8 French polyethylene catheter into the nasopharynx via the nares and applying gentle suction followed by rinsing into mucus traps. Duplicate samples of NPS were obtained both for documentation of RSV infection and for determination of RSV antibody titer. A sample of serum was also obtained. Patients were requested to return in 2-10 wk when similar samples were collected. RSV infection was documented first by identification of viral antigen in nasopharyngeal epithelial cells 